consist mostly of stiffened panels or shells. Researchers have used gradient-based optimizer, discrete optimizer, and the simplex method. A gradient-based optimizer were used in Refs [1-8], a discrete optimizer was used in Refs [9-13], and the simplex method was used in Refs [14], [15].

A literature survey of the optimal design of stiffened panels and shells is presented in Ref. [13]. The survey deals with the type of optimizers that have been used, and the type of buckling analysis, and stiffened panel or shell optimized. Type of stiffened panel or shell refers to whether the panel or shell is stiffened axially, orthogonally or in multiple directions (c.g. gridstiffened panel or shell). According to the review, optimization of panels or shells stiffened in multiple directions were considered in Refs [5], [6], [8], [16]. Grid-stiffened cylinders were considered in Refs [6], [8], [16], and geodesically stiffened flat panels were considered in Ref. [5]. More recently grid-stiffened curved panels were considered in Ref. [13].

The survey also shows that stiffener spacing is treated as a design variable in Refs [1], [2], [7], [8], [14], [15]. A gradient-based optimizer was used in Refs [1], [2], [7], [8], whereas the simplex method [17] was used in Refs [14], [15]. The stiffener panel spacing is a discrete variable since it can be a certain multiple of the length or width of the panel or shell. Both the gradient-based optimizer and the simplex method assume continuous variables and in addition the gradient-based optimizers require derivative information. Therefore as discussed in Jaunky et al. [13] rigorous optimization with respect to stiffener spacing as a design variable is best achieved using a discrete optimizer such as the genetic algorithm [11].

Reddy et al. [16] studied the buckling response of isogrid and orthogrid cylinders with various stiffener spacing using global and local analyses and concluded that, in general, isogrid cylinders are more efficient than orthogrid cylinders. It is also shown [7] that optimizing axially stiffened panels for different fixed stiffener spacings using a gradient-based optimizer can be a good strategy. For panels or shells stiffened in multiple directions, this approach is tedious since one has to consider many starting points in the optimal design process. The stiffener spacings and stiffening configurations can be treated as design variables in an optimization process provided a discrete optimizer is used. A discrete optimizer such as the genetic algorithm has been used to optimize unstiffened or axially stiffened composite panels [9-13], and for other engineering problems [18]. Haftka et al. [9-12] showed the efficiency of the genetic algorithm in dealing with discrete design variables for optimizing composite pancls. They treated the skin and/or stiffener laminate as discrete variables since in practical applications, the ply orientations are limited to 0,90 or $\pm 45^{\circ}$ and the lamincte thickness can only be integer multiples of comm rrcially available ply thickness. Jaunky et al. [13] optimized flat and curved grid-stiffened panels with stiffen $2 r$ height and thickness, skin laminate, stiffener spacings and stiffening configuration as design variables with a global buckling constraint only and showel the efficiency of the genetic algorithm in dealing; with all these discrete design variables that affect he buckling response of grid-stiffened panels.

The literature survey [13] also comments on the bucklir $g$ analyses that have been used. Finite element analysi; [6], discrete analysis [5], PASCO [19] type analysi; [3], and global and local analyses. The merits of these types of analyses are discussed in Jaunky et al. [13]. Most researchers have used global and local analyses, for example Refs [1], [2], [7], [8], [13-16]. Global and local analyses can be made computationally very efficient. Researchers have neglected the anisotropic properties of skin segments in the local buckling analysi:- and also the curvature of the skin segments. Restrictions on the geometry of the skin segment and loading were imposed in order to obtain a closed-form solution for the buckling response. In some cases the eccentricities of the stiffener were even neglected. The main problem of assessing the local buckling of the skin se:sment was the non-availability of computationally efficient and accurate buckling analyses for curved skin seg̨ments with anisotropic material properties, and differer t planform geometry (e.g. general triangular and art itrary quadrilateral geometry). In Jaunky et al. [13] accurate buckling analyses [21-23] were used for global and local analyses, and the occurrence of non-sinultaneous global and local failures were used as this condition leads to designs that are less sensitive to imperfe:tions as discussed in Simitses [15].

The present paper presents the analysis and weight optimizition strategy for grid-stiffened composite circular cylindrical shells subjected to axial load and a global huckling design constraint as well as strength constrai tts using the genetic algorithm. Design variable; are the stiffener height and thickness, skin laminate, stiffener spacings and stiffening configuration. It is intended to be a design tool that can be used as a proliminary design stage for grid-stiffened cylinders for aircraft fuselage or launch vehicle application. In the authors' opinion such a tool for cylinders stiffenec in multiple directions is lacking. The results are presented and discussed for cylinder designs with and without strength or strain constraints which explains the damage tolerant characteristics of gridstiffened structures [20].

\subsection{Sheil buckling analysis}

The tuckling analysis of grid-stiffened composite shells su jected to combined loads requires several key 
steps. In the present study, acceptable designs are those which buckle globally and do not exhibit any local skin buckling or stiffener crippling. The first step in the design process is to assess the global buckling response of a grid-stiffened shell. Once this global buckling response is determined, the second step is to determine the local skin buckling response for the quadrilateral and/or triangular skin segments between the stiffeners. The third step is to determine whether stiffener buckling or stiffener crippling has occurred at this global buckling load level.

The global buckling analysis is based on a RayleighRitz method using a first-order shear-deformation theory and the improved smeared-stiffener modeling approach discussed in Ref. [21] that accounts for skinstiffener interactions. It is shown [21] that buckling loads for stiffened panels with different stiffening configurations obtained using the improved smeared stiffener theory are in good agreement with results obtained using detailed finite element analysis. The cylinder is assumed to be simply supported and hence the Rayleigh-Ritz method for the global analysis assumes the following mode shape for the transverse deflection $w$ :

$$
w=\sum_{i=1}^{N}\left(A_{m_{i},} \sin \frac{n_{i} y}{R}+B_{m, n_{i}} \cos \frac{n_{i} y}{R}\right) \sin \frac{m_{i} \pi x}{L}
$$

where $L$ and $R$ are the length and radius of the cylindrical shell, respectively, and $N$ is the number of terms in the Fourier series. The coordinate system for the cylinder is shown in Fig. 1.

The buckling analysis of local skin segments is also based on a Rayleigh-Ritz analysis using a first-order, shear-deformation theory and accounts for material anistropy. Boundary restraints on the skin segments are provided by the stiffeners and hence, the analysis must be capable of accommodating a variety of boundary conditions and a variety of skin-segment shapes [22], [23]. In most cases, the skin segments for grid-stiffened panels will have either a general parallelogram- or a general triangular-shaped planform. The skin segments are assumed to have simply supported boundary conditions in the present study. It is shown [22], [23] that the buckling analyses presented for arbitrary anisotropic quadrilateral plates and general triangular anisotropic plates can accommodate different boundary conditions, and provide buckling loads that are in very good agreement with finite element analysis and existing solutions. The Rayleigh-Ritz buckling analysis method for global and local analysis makes use of the Sanders-Koiter shell theory [24], [25]. This shell theory provides buckling loads that are in good agreement with finitc element analysis compared to other shell theories as shown in Refs [26], [27].

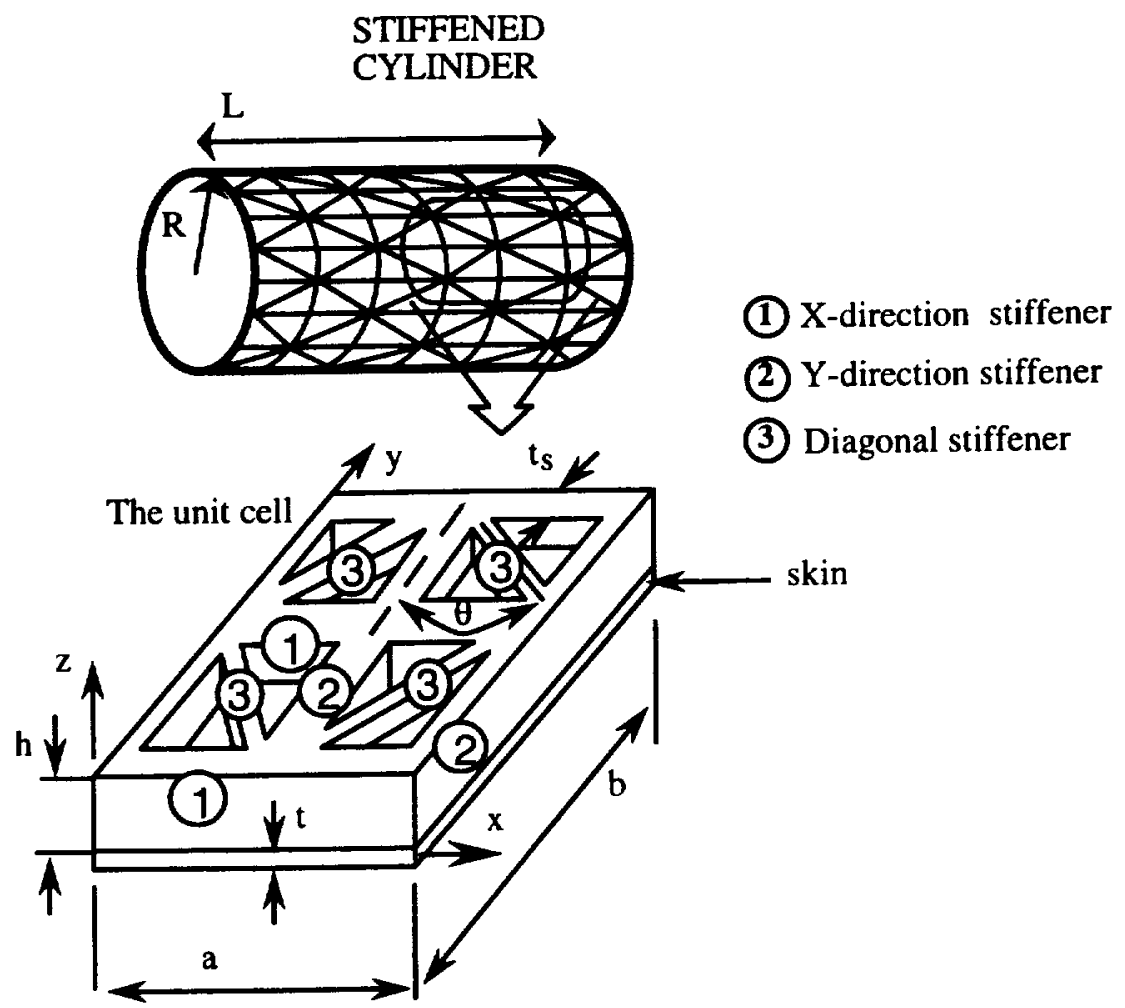

Fig. 1. Unit cell of a grid-stiffened cylinder showing design yariables. 
In addition to analyzing the local skin segment for buckling, the local stiffener segments must be analyzed to determine whether stiffener crippling will occur. Reference [16] provides a method for determining the crippling load of a stiffener segment. Accordingly, the stiffener segment is assumed to be clamped at the nodes or intersection points of the stiffeners while the edge of the stiffener along the stiffener-skin attachment line is assumed to be simply supported.

The global buckling load is assumed to be a scalar multiple of the design load and has the form

$$
N_{\mathrm{t}}=\lambda_{\mathrm{G}} N_{\mathrm{I}}
$$

where $N_{1}$ is the applied prebuckling axial load and represents the design load. Once the global buckling load factor $\left(\lambda_{\mathrm{G}}\right)$ has been determined using the improved smeared stiffener theory, the loads acting on the stiffener and skin segments have to be determined by distributing the loads based on the extensional stiffness of the skin and the stiffener. The procedure for distributing the applied loads for a general gridstiffened panel is discussed in Refs [5], [26] and is the same for a general grid-stiffened circular cylindrical shell. The loads acting on the skin and stiffener segments are computed based on a global load of $N_{x}=\lambda_{\mathrm{G}} N_{1}$ and these loads are used to determine the local buckling load factor of the skin $\left(\lambda_{\mathrm{sk}}\right)$, local crippling factors of axial stiffener segment $\left(\lambda_{1}\right)$, transverse stiffener segment $\left(\lambda_{2}\right)$ and diagonal stiffener segment, $\left(\dot{\lambda}_{3}\right)$.

$$
\lambda_{i}=\frac{\text { critical load of local segment }}{\text { load in local segment due to } \lambda_{G} \times N_{1}}
$$

where $i=1,2,3$ and sk. These local buckling and crippling load factors describe the buckling characteristics of the stiffened cylinder and is as follows

- For $\lambda_{\text {sk }}, \lambda_{1}, \lambda_{2}, \lambda_{3} \geq 1.0$, the cylinder buckles globally at an axial load of $\lambda_{\mathrm{G}} N_{1}$, i.e. $\lambda_{\mathrm{cr}}=\lambda_{\mathrm{G}}$.

- If one of $\lambda_{\text {sk }}, \lambda_{1}, \lambda_{2}, \lambda_{3}<1.0$, then the stiffened cylinder buckles locally. If $\lambda_{\text {sk }}<1.0$, then skin buckling occurs and if $\lambda_{1}<1.0$ then crippling of the axial stiffener occurs. For this case, $\lambda_{\mathrm{cr}}=\lambda_{i} \times \lambda_{\mathrm{G}}$ where $\lambda_{1}<1.0$, and $i$ can be any one of sk, 1, 2 or 3 .

- If more than one of $\lambda_{\text {sk }}, \lambda_{1}, \lambda_{2}$ and $\lambda_{3}$ are $<1.0$, then local buckling of the stiffened cylinder occurs and $\lambda_{\mathrm{wT}}=\lambda_{i} \times \lambda_{\mathrm{g}}$ where $\lambda_{i}$ is the minimum of any of $\lambda_{\mathrm{sk}}, \lambda_{1}$, $\lambda_{2}$ or $\lambda_{3}$ with values $<1.0$.

\section{Strain analysis}

The critical buckling load of the stiffened cylinder is $\lambda_{\mathrm{cr}} N_{1}$ where $\lambda_{\mathrm{cr}}$ takes on values as discussed previously and based on this load value the loads acting on the skin and stiffener segments are obtained [5], [26]. For an axitl load in the skin segment of $N_{\text {xsk }}$, and the loads in axiil, transverse and diagonal stiffener segments of $N_{x 1}, N_{2}$ and $N_{x 3}$, respectively, the axial membrane strain the sk $\mathbf{n}$ and stiffener segments are

$$
\begin{aligned}
& \varepsilon_{x \mathrm{sk}}^{0}=a_{11}^{(\mathrm{sk})} N_{x \mathrm{sk}}+a_{12}^{(\mathrm{skl})} N_{\mathrm{rsk}}+a_{16}^{(\mathrm{sk})} N_{x \mathrm{ysk}} \\
& \varepsilon_{x 1}^{0}=: a_{11}^{(1)} N_{x 1} \\
& \varepsilon_{x 2}^{0}=: a_{11}^{(2)} N_{x 2} \\
& \varepsilon_{x 3}^{0}=a_{11}^{(3)} N_{x 3}
\end{aligned}
$$

where $\varepsilon_{x \mathrm{sk}}^{0}, \varepsilon_{x 1}^{0}, \varepsilon_{x 2}^{0}$ and $\varepsilon_{x 3}^{0}$ are the axial membrane strains in the skin segment, axial, transverse and diagonal stiffener s:gments respectively. The quantities $a_{i j}^{(\mathrm{sk})}, a_{11}^{(1)}, a_{11}^{(2)}$ and $a_{1}^{(3)}$ are axial flexibilities of the skin, axial, transverse and diagonal stiffeners respectively.

The strain level factors for the skin, axial, transverse and dixgonal stiffener segment are

$$
\begin{aligned}
& S_{\mathrm{sk}}=\left(\varepsilon_{\mathrm{xsk}}^{0}\right)_{a l} / \varepsilon_{\mathrm{xsk}}^{0} \\
& S_{1}=\left(\varepsilon_{\mathrm{xst}}^{0}\right)_{a l} / \varepsilon_{x 1}^{0} \\
& S_{2}=\left(\varepsilon_{\mathrm{rst}}^{0}\right)_{a l} / \varepsilon_{x 2}^{0} \\
& S_{3}=\left(\varepsilon_{x \mathrm{~s}}^{0}\right)_{a l} / \varepsilon_{x 3}^{0}
\end{aligned}
$$

where $\left(\varepsilon_{x s k}^{0}\right)_{a l}$ and $\left(\varepsilon_{x \mathrm{st}}^{0}\right)_{a l}$ are the allowable axial memb ane strains in the skin and stiffeners, respectively. The values for $\left(\varepsilon_{x s k}^{0}\right)_{a l}$ and $\left(\varepsilon_{\mathrm{xst}}^{0}\right)_{a l}$ are taken from D. R. Ambur (pers. commun.).

These global and local buckling analysis methods and the strain analysis have been integrated into a computer code to provide a computationally efficient tool for predicting the buckling load and the strain level fictors for grid-stiffened composite circular cylindrical hells subjected to axial compression.

\section{Shell design procedure}

The design variables for a grid-stiffened composite shell a:e the axial and transverse stiffener spacings ( $a$, $b$ ), the stiffening configuration (ICON), which is the combination of axial, transverse and diagonal stiffeners, the skin laminate $(L A M I)$, and the height $(h)$ and thickness $\left(t_{\mathrm{s}}\right)$ of the stiffener (see Fig. 1). Except for the height of the stiffener, these design variables take o 1 discrete values. Hence gradient-based optimization methods are not suitable for optimal design grid-stiffened shells. Furthermore, owing to manufacturing constraints a 'family' of good designs is needed rather than a single point design.

The genetic algorithm is a method for 'evolving' a given lesign problem to a family of near-optimum design! [10], [11], [13], [18]. Stochastic processes are used $t)$ generate an initial population of individual 
designs and the process then applies principles of natural selection and survival of the fittest to find improved designs. Furthermore, since the discrete design procedure works with a population of designs it can explore a large design space and climb different hills. This is a major advantage as the converged solution may contain many optima of comparable performance. The cost of having a large number of function evaluations is offset by the fact that a large number of optimum solutions are now available. The population or family of good designs produced by using the genetic algorithm may include the global optimum design, rather than a single design. Hence, it is an appropriate tool for designing general grid-stiffened composite shells.

\section{Design problem definition}

The present design problem is to minimize the weight of a grid-stiffened composite circular cylindrical shell given the design loading condition, the length and radius of the cylinder and the material properties for the skin and stiffeners. The design variables include stiffener spacings $(a, b)$, the stacking sequence of the skin, stiffener layout, stiffener thickness $\left(t_{\mathrm{s}}\right)$, and stiffener height $(h)$ as shown in Fig. 1. All stiffeners are assumed to be of the same height and thickness for manufacturing and assembly purposes. The design sought here is a cylinder of minimum weight in a certain design space with buckles globally at the design loads while the axial membrane strain in the skin and the stiffener segments do not exceed the allowable axial membrane strain $\left(\varepsilon_{x \mathrm{sk}}^{0}\right)_{a l}$ and $\left(\varepsilon_{x \mathrm{st}}^{0}\right)_{a l}$ respectively. This design problem cam be defined by setting up the optimization procedures in the following way. First, the global buckling load is assumed to be a scalar multiple of design loads and has the form

$$
N_{x}=\lambda_{\mathrm{G}} N_{1}
$$

where $N_{1}$ is the applied in-plane prebuckling load. This value represents the design loads for the grid-stiffened cylinder. Second, the design constraints imposed on panel include:

- The critical buckling load should be greater than or equal to the design loads, that is, $\lambda_{\mathrm{G}} \geq 1$.

- Skin segments should not buckle at the critical buckling load, that is, $\lambda_{\text {sk }} \geq 1$.

- Stiffener segments should not cripple at the critical buckling load, that is, $\lambda_{1}, \lambda_{2}, \lambda_{3} \geq 1$.

- The axial membrane strain in the skin segment should be less than or equal to $\left(\varepsilon_{\mathrm{rsk}}^{0}\right)_{a}$, that is, $S_{\mathrm{sk}} \geq 1$.

- The axial membrane strain in the stiffener segment should be less than or equal to $\left(\varepsilon_{x s t}^{0}\right)_{a l}$, that is, $S_{1}, S_{2}$, $S_{3} \geq 1$.
The general form of each constraint equation is written as

$$
g_{j}=\left\{\begin{array}{l}
\left(1 / \lambda_{j}-1\right) \leq 0.0 \\
\left(1 / S_{j}-1\right) \leq 0.0
\end{array} \quad j=1, \ldots, \mathrm{N}_{\mathrm{c}}\right.
$$

Finally, the 'fitness' expression based on exterior penalty function approach is

$$
\begin{aligned}
\text { Fitness } & =\left(\frac{Q}{F\left(\mathbf{X}, r_{i}\right)}\right) \\
& =\mathbf{M a x} \frac{Q}{W(\mathbf{X})+r_{i} \sum_{j}^{N_{k}}\left[\left|g_{i}(\mathbf{X})\right|+g_{j}(\mathbf{X})\right]^{2}}
\end{aligned}
$$

- where $\mathbf{X}=$ design variable vector

- $F\left(\mathbf{X}, r_{i}\right)=$ modified objective function

- $W(\mathbf{X})=$ weight of panel per unit area

- $r_{i} \sum_{j}^{N_{i}}\left[\left|g_{j}(\mathbf{X})\right|+g_{j}(\mathbf{X})\right]^{2}=$ penalty function

- $Q=$ normalizing constant

- $N_{\mathrm{c}}=$ number of design constraints

- $r_{i}=$ penalty parameter

- $i=$ generation or iteration cycle in the optimization procedure.

\section{Design process based on genetic algorithm}

Implementation of the genetic algorithm [11] is shown schematically in Fig. 2. The design process

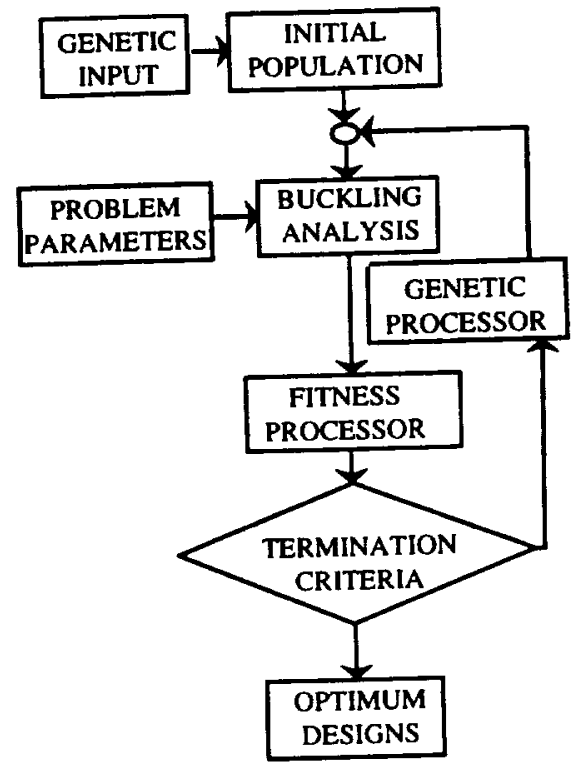

Fig. 2. Flow chart for the optimization procedure using the genetic algorithm. 
begins with a random selection of a specified number of designs which comprise the initial population (i.e. first generation) for the genetic algorithm. Material properties, radius and length of the cylinder, boundary conditions of the skin segment and design loadings are input to the analysis processor routine. The buckling analysis is performed which provides the critical eigenvalues for the global buckling response of the gridstiffened cylinder, the local buckling response of the skin and stiffener segments, and the strain level factors of the skin and stiffener segments. The weight of the grid-stiffened cylinder is also computed. This procedure is repeated for each design configuration in the population. The 'fitness' processor then evaluates the 'fitness' of each design using eqn (8) and assigns a rank based on the fitness expression or objective function. The current population of design configurations is then processed by the genetic operators (crossover, mutation and permutation) to create a new population of design configurations for the next generations which combines the most desirable characteristics of previous generations. Designs from previous generations may be replaced by new ones (i.e. children) except for the 'most fit' designs (i.e. parents) which are always included in the next generation. The process is repeated until design convergence is obtained, which is defined herein by specifying a maximum number of generations (NSTOP) that may occur without improvement in the hest design. The design procedure will now be demonstrated on gridstiffened cylinders with and without the axial membrane strain constraint in the skin and stiffener segments to study the influence of constraints on the axial membrane strain on the optimal designs.

\subsection{Numerical results for grid-stiffened cylinders}

Results are presented for composite grid-stiffened cylinders subjected to axial compression in order to demonstrate the changes in optimal designs due to constraints on the axial membrane strain. These changes will depend on the loading, stiffening configuration (ICON), stiffener spacings $(a, b)$ and the skin laminate $(L A M I)$. The cylinders studied in examples 1 and 2 are $7391 \mathrm{~mm}$ long, have a radius of $2426 \mathrm{~mm}$ and have blade stiffeners made of unidirectional materials [16]. The nominal ply mechanical properties are: $E_{11}=63218 \mathrm{~N} \quad \mathrm{~mm}^{2} ; \quad E_{22}=5604$
Table 1

Design space for design variable ICON and $L A M I$

\begin{tabular}{lll}
$\begin{array}{l}\text { Integer } \\
\text { value }\end{array}$ & \multicolumn{1}{c}{$L A M I$} & \multicolumn{1}{c}{ ICON } \\
1 & {$[ \pm 45 / 0]_{2 \mathrm{~s}}$} & Axial stiffeners \\
2 & {$[ \pm 45 / 90]_{2 \mathrm{~s}}$} & Axial stiffeners \\
3 & {$[ \pm 45 / 0 / 90]_{2 s}$} & Axial and transverse stiffeners \\
4 & {$\left[ \pm 45 / 0_{2}\right]_{2 s}$} & Diagonal stiffeners \\
5 & {$\left[ \pm 45 / 90_{2}\right]_{2 s}$} & Axial and diagonal stiffeners \\
6 & {$\left[ \pm 45 / 0_{2} / 90\right]_{2 s}$} & Transverse and diagonal stiffeners \\
7 & {$\left[ \pm 45 / 0 / 90_{2}\right]_{2 s}$} & Axial, transverse and diagonal stiffeners \\
8 & {$\left[ \pm 45 / 0_{2} / 90_{2}\right]_{2 s}$} & No stiffeners
\end{tabular}

$\mathrm{N} \mathrm{mm}^{-2} ; \quad G_{12}=G_{13}=G_{23}=2973 \quad \mathrm{~N} \quad \mathrm{~mm}^{-2}$ and $v_{12}=0.300$. The mass density of the material $\rho$, is $1.578 \mathrm{E}-06 \mathrm{~kg} \mathrm{~mm}^{-3}$. The probabilities used for crossover, nutation and permutation are 1.0, 0.10 and 0.95 , respectively, and the number of discrete values that each design variable can accommodate is eight, which is a limitation of the FORTRAN code for the genetic algorith $m$ being used. The design variables ICON and $L A M I$ are described in Table 1

\subsection{Example 1}

The irst example is a cylinder subjected to an axial load of $N_{1}=175.2 \mathrm{~N} \mathrm{~mm}^{-1}$ which represents a cylinder case st $\iota$ died in Ref. [16]. The design variables are the axial ard transverse stiffener spacings, the height and thickne: $s$ of the stiffeners, the stiffening configuration $(I C O N)$ and the skin laminate $(L A M I)$. The thickness of each ply of the skin laminate for this example is $0.1524 \mathrm{~mm}$. The design space for $a, b, h$ and $t_{\mathrm{s}}$ is shown in Tabl: 2. The height and thickness of the stiffener $(h / t)$ is chosen such that the aspect ratio of the stiffener is betwe en 4 and 10, and the stiffener thickness is an integer multiple of $0.1524 \mathrm{~mm}$ due to manufacturing constrai its. The minimum values of the stiffener spacings are also due to manufacturing constraints. A population size of 20 is used, NSTOP $=15$, and the penalty parameter $r_{i}=100000$ at any iteration. The allowabl : strains $\left(\varepsilon_{x \mathrm{sk}}^{0}\right)_{a l}$ and $\left(\varepsilon_{\mathrm{xs}}^{0}\right)_{a l}$ are 2428 microstrain and $109: \therefore$ microstrain, respectively (D. R. Ambur, pers. commun.).

The lesults from design optimization with and without strain constants are shown in Table 3. The minimunı weight for this cylinder is $481.53 \mathrm{~kg}$ compare 1 to the weights of $479.90 \mathrm{~kg}$ for an isogrid

Table 2

Design space for $a, b, h$ and $t_{\mathrm{s}}$ for Examples 1 and 2

$\begin{array}{lll}a, \mathrm{~mm} & 217.4 & 211.2\end{array}$

$\begin{array}{lccc}b, \mathrm{~mm} & 525.5 & 211.2 & 205.3 \\ h, \mathrm{~mm} & 10.16 & 508.0 & 491.6 \\ & 10.46 & 10.80\end{array}$

$\begin{array}{rrrr}1, \mathrm{~mm} & 10.16 & 10.46 & 10.80 \\ \iota_{\mathrm{n}} \mathrm{mm} & 1.22 & 1.37 & 1.52\end{array}$
199.7

476.3

$\begin{array}{rr}1.52 & 11.11 \\ & 1.68\end{array}$

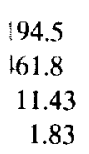

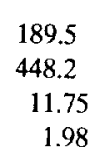

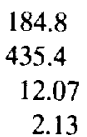

180.3

423.3

12.38 
Table 3

Best designs obtained by genetic algorithm for grid-stiffened cylin$\operatorname{ders}\left(N_{x}=175.2 \mathrm{~N} \mathrm{~mm}^{-1}\right)$

Design variables $(\mathrm{mm})$

$$
\text { Weight }(\mathbf{k g})
$$

$a=189.5, b=525.5$

$h=10.16, t_{\mathrm{s}}=1.22$

$L A M I=4, I C O N=6$

$a=189.5, b=491.6$

$h=10.16, t_{\mathrm{s}}=1.22$

$L A M I=4, I C O N=6$

$a=189.5, b=476.3$

$h=10.16, t_{\mathrm{s}}=1.22$

$L A M I=4, I C O N=6$
481.53

481.72

481.5

\begin{tabular}{rlrl} 
& $\lambda_{\mathrm{i}}$ & \multicolumn{1}{c}{$S_{\mathrm{i}}$} \\
$\lambda_{\mathrm{i}}=1.008$ & $S_{\mathrm{sk}}=2.68$ \\
$\lambda_{\mathrm{sk}}=1.009$ & $S_{3}=105.1$ \\
$\lambda_{33}=55.1$ & \\
$\lambda_{\mathrm{i}}=1.025$ & $S_{\mathrm{sk}}=2.63$ \\
$\lambda_{\mathrm{sk}}=1.011$ & $S_{3}=81.7$ \\
$\lambda_{3}=43.4$ & \\
$\lambda_{\mathrm{i}}=1.034$ & $S_{\mathrm{sk}}=2.61$ \\
$\lambda_{\mathrm{sk}}$ & $=1.012$ & $S_{3}=72.6$ \\
$\lambda_{3.3}$ & $=38.8$ & &
\end{tabular}

cylinder and $477.63 \mathrm{~kg}$ for an orthogrid cylinder [16]. Only three optimal designs are identified here and they all buckle globally at their respective $\lambda_{\mathrm{g}}$ values since $\lambda_{\mathrm{sk}}$ and $\lambda_{3}$ values are greater than 1 . For this case, the optimal designs have $I C O N=6$, that is the stiffening configuration has transverse and diagonal stiffeners only, and $L A M I=4$, which corresponds to a skin laminate which a stacking sequence of $\left[ \pm 45 / 0_{2}\right]_{2 s}$, $h=10.16 \mathrm{~mm}$ and $t_{\mathrm{s}}=1.22 \mathrm{~mm}$. In this case, the optimal designs without strain constraints are the same as the optimal design with strain constraints. The buckling-resistant design for this load case results in in-plane stiffness values that provide large strain level factors. This analysis suggests that the cylinder design satisfies both buckling and strength requirement. Convergence is obtained after 49 generations for the case without strain constraints and after 77 generations for the case with strain constraints.

\subsection{Example 2}

The second example is for a grid-stiffened cylinder as in Example 1 but subjected to an axial load of $N_{1}=315.3 \mathrm{~N} \mathrm{~mm}^{-1}$. For this case, the stiffening configuration with axial and diagonal stiffeners (ICON) only has been selected. The design variables are the axial and transverse stiffener spacings, the height and thickness of the stiffeners, and the skin laminate with each ply being $0.2032 \mathrm{~mm}$ thick. The design space for the skin laminate is the same as shown in Table 1 , and the design space for $a, b, h$ and $t_{\mathrm{s}}$ is shown in Table 2 . The material properties, the genetic parameters and the strain allowables for Example 2 are the same as in Example 1. The optimal designs without strain constraints are shown in Table 4 , whereas the optimal designs with strain constraints are shown in Table 5. Only three optimal designs are shown here for each case.

All the designs in Tables 4 and 5 buckle globally since $\lambda_{\mathrm{sk}}, \lambda_{1}$ and $\lambda_{3}$ are all greater than one. The
Table 4

Best designs obtained by genetic algorithm for grid-stiffened cylinder with no constraints on strain and $I C O N=5,\left(N_{x}=315.3 \mathrm{~N} \mathrm{~mm}{ }^{1}\right)$

Design variables
$(\mathrm{mm})$

Weight
$(\mathrm{kg})$

$a=217.4, b=423.3$

$h=11.43, t_{\mathrm{s}}=1.83$

634.1

$i_{\mathrm{ii}}=1.0088$

$L A M I=4$

$a=194.5, b=435.4$

$h=10.16, t_{\mathrm{s}}=1.98$

$L A M I=3$

$a=194.5, b=423.3$

$h=10.16, t_{\mathrm{s}}=1.98$

$L A M I=3$

6.34 .8

$\lambda_{\mathrm{sk}}=1.078$

$\lambda_{1}=1.11, \lambda_{3}=24.6$

$\lambda_{i}=1.0447$

$\lambda_{\mathrm{k}}=1.051$

$\lambda_{1}=1.04, \lambda_{3}=35.3$

635.5

$$
\begin{aligned}
& \lambda_{i}=1.0541 \\
& i_{i_{\mathrm{k}}}=1.077 \\
& \lambda_{1}=1.04, \lambda_{3}=32.1
\end{aligned}
$$

optimal designs obtained with strain constraints are $\approx 4-6 \mathrm{~kg}$ heavier than the optimal designs obtained without strain constraints for approximately the same global buckling load. The designs in Table 5 have larger axial stiffener spacing $(a)$ than the second and third designs in Table 4. For the designs in Table 5, the strain level factors of the axial stiffeners $\left(S_{1}\right)$, are very close to unity whereas the strain factors for the diagonal stiffeners $\left(S_{1}\right)$ are much larger. The increase in structural weight of the optimal design for this case over the designs in Example 1 is due to the increase in load and the choice of stiffening configuration. Even for this load condition, imposing strain constraints does not result in a significant increase in weight. Convergence is obtained after 18 generations for the case without strain constraints and after 41 generations for the case with strain constraints.

\subsection{Example 3}

The third examplc is a grid-stiffened cylinder subjected to an axial load of $N_{1}=350.4 \mathrm{~N} \mathrm{~mm}^{-1}$. This represents a generic, wide-body transport aircraft

\begin{tabular}{|c|c|c|c|}
\hline $\begin{array}{l}\text { Design variables } \\
(\mathrm{mm})\end{array}$ & $\begin{array}{c}\text { Weight } \\
(\mathrm{kg})\end{array}$ & $i_{i}$ & $S_{i}$ \\
\hline $\begin{array}{l}a=211.2, b=423.3 \\
h=11.11, t_{\mathrm{v}}=1.98 \\
L A M I=4\end{array}$ & 6.38 .0 & $\begin{array}{l}\lambda_{i \mathrm{i}}=1.0113 \\
\lambda_{\mathrm{ik}}=1.101 \\
\lambda_{1}=1.36, \lambda_{3}=32.9\end{array}$ & $\begin{array}{l}S_{\mathrm{k}}=2.07 \\
S_{1}=1.08 \\
S_{3}=27.2\end{array}$ \\
\hline $\begin{array}{l}a=205.3, b=423.3 \\
h=11.11, t_{s}=1.98 \\
L A M I=4\end{array}$ & 639.0 & $\begin{array}{l}\lambda_{\mathrm{i}}=1.0100 \\
\lambda_{\mathrm{ik}}=1.126 \\
\lambda_{1}=1.38, \lambda_{3}=36.2\end{array}$ & $\begin{array}{l}S_{\mathfrak{k}}=2.08 \\
S_{1}=1.08 \\
S_{3}=29.8\end{array}$ \\
\hline $\begin{array}{l}a=211.2, b=423.3 \\
h=11.75, t_{\mathrm{b}}=1.98 \\
L A M I=4\end{array}$ & 641.5 & $\begin{array}{l}\lambda_{\mathrm{i}}=1.0600 \\
\lambda_{\mathrm{sk}}=1.053 \\
\lambda_{1}=1.19, \lambda_{3}=28.9\end{array}$ & $\begin{array}{l}S_{\text {,k }}=1.99 \\
S_{1}=1.03 \\
S_{3}=26.0\end{array}$ \\
\hline
\end{tabular}

Table 5

Best designs obtained by genetic algorithm for grid-stiffened cylinder with constraints on strain and $I C O N=5\left(N_{x}=315.3 \mathrm{~N} \mathrm{~mm}^{-1}\right)$ 
fuselage section between two frames. The radius of the cylinder is $2426 \mathrm{~mm}$ and the length is $559 \mathrm{~mm}$. The design variables are the transverse stiffener spacing, the height and thickness of the stiffeners and the skin laminate with each ply being $0.2286 \mathrm{~mm}$ thick. The optimization is performed with the stiffening configuration selected to $I C O N=1$ and $I C O N=5$. For the case when $I C O N=5$, the axial stiffener spacing is $159.7 \mathrm{~mm}$. The design space for the skin laminate is the same as shown in Table 1 and the design space for $b, h$ and $t_{\mathrm{s}}$ is shown in Table 6 . The material properties and the genetic parameters for Example 3 is the same as in Example 1. Three optimal designs obtained with strain constraints are shown in Table 7 for the axially stiffened cylinders and in Table 8 for the cylinders stiffened with axial and diagonal stiffeners. For axially stiffened cylinders convergence is obtained at 38 gener- ations, while for the cylinders with axial and diagonal stiffen $r$ rs, convergence is obtained at 20 generations.

All the optimal designs in Tables 7 and 8 buckle globally and do not violate any strain constraint. Howerer, the optimal designs with ICON $=5$ are slightly heavier than the optimal designs with $I C O N=1$. The buckling behavior of the first design in Table 7 and Table 8 subjected to an axial load of $N_{x}=3: 0.4 \mathrm{~N} \mathrm{~mm}^{-1}$ and combined transverse compression $\left(N_{y}\right)$, and shear $\left(N_{x y}\right)$ is sought to determine their capability to support additional in-plane loads. A load combiration for $N_{x}=350.4 \mathrm{~N} \mathrm{~mm}^{-1}, N_{y}$ and $N_{x y}$ is sought in such a way that the cylinder can still support an axial load of $N_{x}=350.4 \mathrm{~N} \mathrm{~mm}^{-1}$, i.e. $\lambda_{\mathrm{cr}} \geq 1$ and $\lambda_{\text {cr }} \approx 1$. The results are shown in Table 9 for the axially stiffened cylinder and in Table 10 for the grid-stittened cylinde- with $I C O N=5$. It is seen that the grid-

Table 6

Design space for $h, h, t$, for Example 3

\begin{tabular}{|c|c|c|c|c|c|c|c|c|}
\hline \multirow{4}{*}{$\begin{array}{l}b(\mathrm{~mm}) \\
h(\mathrm{~mm}) \\
t,(\mathrm{~mm})\end{array}$} & \multicolumn{7}{|c|}{ Axially stiffened cylinder, $I C O N=1$} & \multirow[b]{2}{*}{180.3} \\
\hline & 217.4 & 211.2 & 205.3 & 199.7 & 194.5 & 189.5 & 184.9 & \\
\hline & 16.19 & 16.51 & 16.83 & 17.14 & 17.46 & 17.78 & 18.10 & 18.42 \\
\hline & 2.59 & 2.74 & 2.89 & 3.05 & 3.20 & 3.35 & 3.50 & 3.66 \\
\hline \multicolumn{9}{|c|}{ Grid-stiffened cylinder, $I C O A=5$} \\
\hline$h(\mathrm{~mm})$ & 324.3 & 319.0 & 311.0 & 304.8 & 298.8 & 293.1 & 287.6 & 282.2 \\
\hline$h(\mathrm{~mm})$ & 13.36 & 13.65 & 13.97 & 14.29 & 14.67 & 14.92 & 15.24 & 15.56 \\
\hline$t_{v}(\mathrm{~mm})$ & 1.68 & 1.83 & 1.98 & 2.13 & 2.29 & 2.44 & 2.59 & 2.74 \\
\hline
\end{tabular}

Table 7

Best designs obtained by genetic algorithm for axially cylinder with constraints on stra $\mathbf{n},\left(N_{1}=350.4 \mathrm{~N} \mathrm{~mm}^{-1}\right)$

Design variables $(\mathrm{mm})$

$b=217.4, h=16.51$

$\mathrm{l}=2.59, L A M I=4$

$b=211.2, h=16.19$

$t_{\mathrm{s}}=2.59, L A M I=4$

$b=211.2, h=16.51$

$t_{\mathrm{s}}=2.59, L \mathcal{A} M I=4$
Weight $(\mathrm{kg})$

54.4

54.4

54.6

\begin{tabular}{ll}
\multicolumn{1}{c}{$\lambda_{\mathrm{i}}$} & \multicolumn{1}{c}{$S_{\mathrm{i}}$} \\
$\lambda_{\mathrm{s}}=1.0177$ & $S_{\mathrm{sk}}=2.310$ \\
$\lambda_{\mathrm{sk}}=2.803, \lambda_{1}=1.025$ & $S_{1}=1.200$ \\
$\lambda_{\mathrm{G}}=1.0079$ & $S_{\mathrm{sk}}=2.335$ \\
$\lambda_{\mathrm{sk}}=3.004, \lambda_{1}=1.073$ & $S_{1}=1.213$ \\
$\dot{\lambda}_{\mathrm{s}}=1.0285$ & $S_{\mathrm{sk}}=2.295$ \\
$\lambda_{\mathrm{sk}}=2.952, \lambda_{1}=1.018$ & $S_{1}=1.192$ \\
\hline
\end{tabular}

Table 8

Best designs obtained by genetic algorithm for grid-stiffened cylinder with constraints $\mathrm{n}$ strain, $I$ CON $=5\left(N_{x}=350.4 \mathrm{~N} \mathrm{~mm}\right)$

\begin{tabular}{|c|c|c|c|}
\hline Design variables $(\mathrm{mm})$ & Weight (kg) & $\dot{\lambda}_{i}$ & $S_{\mathrm{i}}$ \\
\hline $\begin{array}{l}b=319.0, h=13.36 \\
t_{s}=1.98, L A M I=4\end{array}$ & 55.8 & $\begin{array}{l}{ }_{\mathrm{G}}=1.0368, \lambda_{\mathrm{sk}}=2.341 \\
\mathrm{I}_{1}=1.068, \lambda_{3}=24.6\end{array}$ & $\begin{array}{l}S_{\mathrm{sk}}=2.08 \\
S_{1}=1.98\end{array}$ \\
\hline $\begin{array}{l}b=311.0, h=13.36 \\
c_{v}=1.98, L A M I=4\end{array}$ & 55.9 & $\begin{array}{l},_{\mathrm{G}}=1.0490, \lambda_{\mathrm{sk}}=2.387 \\
\lambda_{1}=1.057, \lambda_{3}=22.79\end{array}$ & $\begin{array}{l}S_{3}=27.0 \\
S_{\text {sk }}=2.064 \\
S_{1}=1.072\end{array}$ \\
\hline $\begin{array}{l}b=304.8, h=13.36 \\
t_{4}=1.98, L A M I=4\end{array}$ & $\ldots \ldots$ & $\begin{array}{l}i_{:}=1.0595, \lambda_{\mathrm{sk}}=2.424 \\
\lambda_{1}=1.049, \lambda_{3}=21.44\end{array}$ & $\begin{array}{l}S_{3}=24.67 \\
S_{\mathrm{sk}}=2.048 \\
S_{1}=1.064 \\
S_{3}=22.96\end{array}$ \\
\hline
\end{tabular}


Table 9

Buckling load factors and strain level factors for axially stiffened cylinder

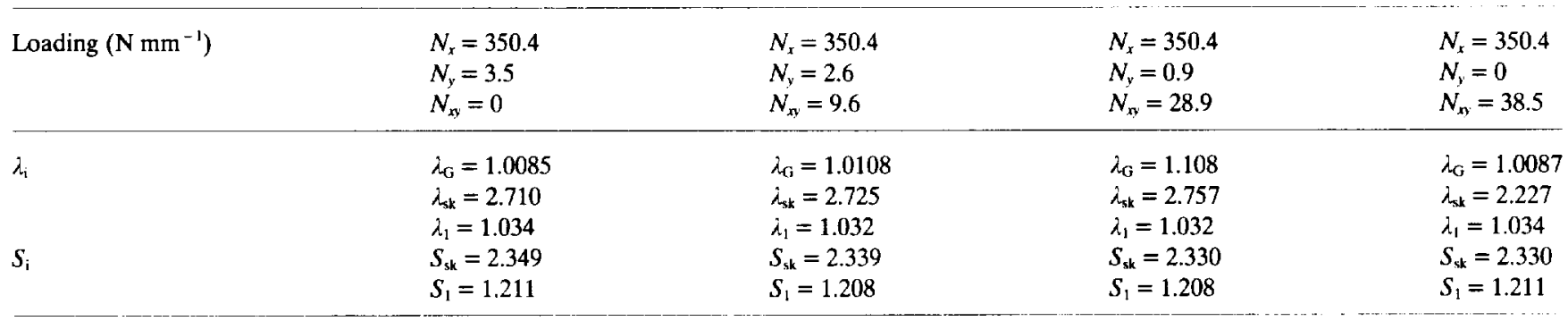

stiffened cylinder can support up to $70.1 \mathrm{~N} \mathrm{~mm}^{-1}$ of transverse compression and $70.1 \mathrm{~N} \mathrm{~mm}^{-1}$ in shear whereas the axially stiffened cylinder can only support additional loads of $3.5 \mathrm{~N} \mathrm{~mm}^{-1}$ in transverse compression and $38.5 \mathrm{~N} \mathrm{~mm}^{-1}$ in shear without exceeding the strain allowables. It is assumed here that the strains $\varepsilon_{y}$ and $\gamma_{x y}$ due to $N_{y}$ and $N_{x y}$ do not produce strains large enough to create failure since $N_{y}$ and $N_{x y}$ are small compared to $N_{x}$. For these loading combinations, both cylinders buckle globally and the constraint on the axial membrane strains in the skin and stiffener are not violated. Hence the grid-stiffened cylinder can sustain larger magnitudes of additional transverse compression and shear loads than the axially stiffened cylinder.

\section{Concluding remarks}

A minimum-weight design optimization tool with global buckling constraint and constraint on the axial membrane strain in the skin and stiffener segments has been developed for grid-stiffened cylinders using global and local buckling analyses and a genetic algorithm. Design variables used are axial and transverse stiffener spacing, stiffener height and thickness, skin-laminate stacking sequence and stiffening configuration. The present design optimization procedure has been validated by comparing with existing results. Results for grid-stiffened cylinders subjected to axial compression indicate that there is no significant difference in weight between optimal designs obtained with an without strain constraints for simply supported cylinders that buckle globally. It is also shown that a gridstiffened cylinder optimized for axial load has an additional load capacity for combined loading larger than for a conventional axially stiffened cylinder. This additional load capability permits load redistribution in the event of structural damage and suggests that a gridstiffened cylinder is more damage tolerant than an axially stiffened cylinder.

\section{Acknowledgements}

The work of the first two authors was supported by NASA Grant NAG-1-1588.

\section{References}

[1] Schmit LA, Kicher TP, Morrow WM. Structural synthesis capability for integrally stiffened waffle plates. AIAA Journal 1963;1:2820-2836.

[2] Jones RT, Hague DS. Application of multivariable search techniques to structural design optimization. NASA CR-2038, June 1972.

[3] Stroud WJ. Optimization of composite structures. IUTAM Proceedings for Mechanics of Composite Materials - Recent Advances. Hashin Z, Harakovich CT (Editors), Blacksburg, VA, 1982.

[4] Yung SS, Haftka RT, Watson LT, Plaut RH. Design of laminated plates for maximum buckling load. Journal of Composite Materials 1989;23:348-369.

[5] Phillips JL, Gurdal Z. Structural analysis and optimum design of geodesically stiffened composite panels. Report CCMS-90-05, Center for Composite Materials and Structures. Blacksburg,

Table 10

Buckling load factors and strain level factors for grid-stiffened cylinder

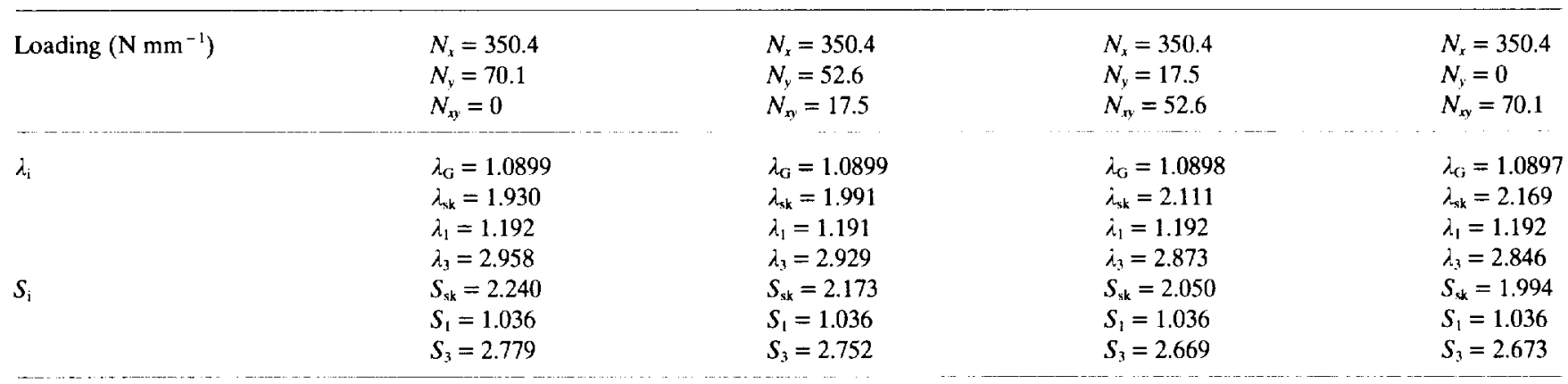


VA: Virginia Polytechnic Institute and State University, July 1990.

[6] Gendron G, Gurdal Z. Optimal design of geodesically stiffened composite cylindrical shell. Proceedings of the 33rd AIAA ASME/ASCE/AHS/ASC Structures, Structural Dynamics and Materials Conference, Dallas, TX, AIAA Paper No. 92-2306-CP, April 13-15, 1992, pp. 2431-2441.

[7] Bushnell D, Bushnell WD. Approximate method for optimum design of ring and stringer stiffened cylindrical panels and shells with local, inter-ring and general buckling modal imperfections. Computers and Structures 1996;59:489-527.

[8] Bushnell D. Recent enhancements to PANDA2. Proceedings of the 37th AIAA/ASME/ASCE/AHS/ASC Structures, Structural Dynamics and Materials Conference, Salt Lake City, UT, AIAA Paper No. 96-1337-CP, April 15-17, 1996, pp. 126-182.

[9] Nagendra S, Haftka RT, Gurdal Z. Stacking sequence optimization of simply supported plates with stability and strain constraints. AIAA Journal 1992;30:2132-2137.

[10] Nagendra S, Haftka RT, Gurdal Z. Design of a blade stiffened composite panel by genetic algorithm. Proceedings of the 34th AIAA/ASME/ASCE/AHS/ASC Structures, Structural Dynamics and Materials Conference, AIAA Paper No. 93-1584-CP, April 1993, La Jolla, CA, pp. 2418-2436.

[11] Leriche R. Haftka RT. Optimization of laminate stacking sequence for buckling load maximization by genetic algorithm. AIAA Journal 1993;31:951-956.

[12] Harrison PN. Leriche R, Haftka RT. Design of stiffened panels by genetic algorithm and response surface approximations. Proceedings of 36th AIAA/ASME/ASCE/AHS/ASC Structures, Structural Dynamics and Materials Conference, New Orleans, LA, AIAA Paper No. 95-1163-CP, April 10-13, 1995, pp. $58-68$.

[13] Jaunky N, Knight NF, Ambur DR. Optimal design of gridstiffened composite panels using global and local buckling analyses. Journal of Aircraft 1998;35(3):478-486.

[14] Simites GJ, Ungbhakorn V. Minimum-weight design of stiffened cylinders under axial compression. AIAA Journal 1975;13(6):750-755.

[15] Simitses GJ, Optimization of stiffened cylindrical shells subjected to destabilizing loads. Structural Optimization: Status and Promise, Progress in Astronautics and Aeronautics, Vol. 150, Manohar P. Kamat (ed.). American Institute of
Ael onautics and Astronautics, Washington, DC, 1992, pp. 663-704.

[16] Reiddy AD, Valisetty RR, Rehfield LW. Continuous filament wol nd composite concepts for aircraft fuselage structures. Jou rnal of Aircraft 1985;22:249-255.

[17] Nel der J.A. Mead R. A simplex method for function minimization. Computer Journal 1964;7:308-313.

[18] Whitney SA. Formulation of genetic algorithm for solution of engineering designs. Old Dominion University, Norfolk, VA, Ma iter's Thesis, May 1995.

[19] An lerson MS, Stroud WJ, Durling BJ, Hennessy KW. PASCO: Stritctural Panel Analysis and Sizing Code. User's Manual. NASA TM 80182, November 1981.

[20] Ro:sse M, Ambur DR. Damage tolerance and failure analysis of a geodesically stiffened structure loaded in axial compression. Proceedings of the 35th AIAA/ASME/ASCE/AHS/ASC Structures, Structural Dynamics and Materials Conference, Hilton Head, SC, AIAA Paper No. 94-1534, April 18-21, 1994, pp. $16 \oint_{1}-1698$.

[21] Jaunky N, Knight NF, Ambur DR. An improved smeared the $)$ ry for buckling analysis of grid-stiffened composite panels. Composite: Part B (formerly) International Journal for Composite Engineering 1996;27B:519-526.

[22] Jaunky N, Kright NF, Ambur D.. Buckling of arbitrary quadrilatt ral anisotropic plates. AIAA Journal 1995;33:938-944.

[23] Jaunky N, Knight NF, Ambur DR. Buckling analysis of general triangular anisotropic plates using polynomials. AIAA Journal 1995;33:2414-2417.

[24] Sanuders, JL Jr. An improved first approximation theory for thil: shells. NASA Report R-24, 1959.

[25] Ko ter WT. A consistent first approximation in general theory of thin elastic shells. The Theory of Thin Elastic Shells, Prc ceedings IUTAM Symposium, Delft, 1959. Amsterdam: No th-Holland Publishing Company, 1960, pp. 12-33.

[26] Jaunky N. Buckling analysis and optimum design of multidirectionally stiffened composite curved panel. Old Dominion Un versity, Norfolk, VA, PhD Dissertation, December 1995.

[27] Yi-Wei Li, Elishaoff I, Starnes JH, Bushnel D. Effect of the thickness variation and initial imperfection on buckling of coriposite cylindrical shells: asymptotic analysis and numerical res alts by BOSOR4 and PANDA2. International Journal of Sol ds and Structures 1997;34(28):3755-3767. 